\title{
Unexpected Oligomerization of Small $\alpha$-Dicarbonyls for Secondary Organic Aerosol and Brown Carbon Formation
}

\author{
Yixin Li, Yuemeng Ji,* Jiayun Zhao, Yuan Wang, Qiuju Shi, Jianfei Peng, Yuying Wang, Chunyu Wang, \\ Fang Zhang, Yuxuan Wang, John H. Seinfeld, and Renyi Zhang*
}

Cite This: Environ. Sci. Technol. 2021, 55, 4430-4439

Read Online

ACCESS | 씨 Metrics \& More | 回 Article Recommendations

ABSTRACT: Large amounts of small $\alpha$-dicarbonyls (glyoxal and methylglyoxal) are produced in the atmosphere from photochemical oxidation of biogenic isoprene and anthropogenic aromatics, but the fundamental mechanisms leading to secondary organic aerosol (SOA) and brown carbon $(\mathrm{BrC})$ formation remain elusive. Methylglyoxal is commonly believed to be less reactive than glyoxal because of unreactive methyl substitution, and available laboratory measurements showed negligible aerosol growth from methylglyoxal. Herein, we present experimental results to demonstrate striking oligomerization of small $\alpha$-dicarbonyls leading to $\mathrm{SOA}$ and $\mathrm{BrC}$ formation on sub-micrometer aerosols. Significantly more efficient growth and browning of aerosols occur upon exposure to methylglyoxal than glyoxal under atmospherically relevant concentrations and in the absence/presence of gas-phase ammonia and formaldehyde, and

Surface-limited Aerosol Growth

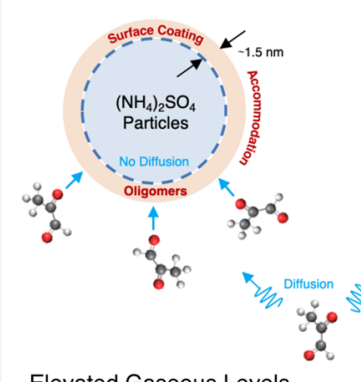

Elevated Gaseous Levels
Supporting Information

Volume-limited Aerosol Growth

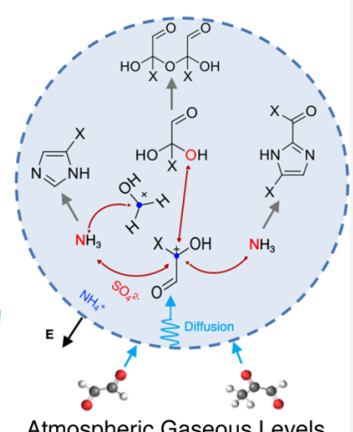
nonvolatile oligomers and light-absorbing nitrogen-heterocycles are identified as the dominant particle-phase products. The distinct aerosol growth and light absorption are attributed to carbenium ion-mediated nucleophilic addition, interfacial electric field-induced attraction, and synergetic oligomerization involving organic/inorganic species, leading to surface- or volume-limited reactions that are dependent on the reactivity and gaseous concentrations. Our findings resolve an outstanding discrepancy concerning the multiphase chemistry of small $\alpha$-dicarbonyls and unravel a new avenue for SOA and $\mathrm{BrC}$ formation from atmospherically abundant, ubiquitous carbonyls and ammonia/ammonium sulfate.

\section{INTRODUCTION}

An annual amount of $\sim 2000$ teragrams $\left(\mathrm{Tg} \mathrm{a}^{-1}\right)$ of volatile organic compounds (VOCs) is emitted into the atmosphere from natural and anthropogenic sources. ${ }^{1,2}$ Photochemical oxidation of VOCs has profound implications for air quality, human health, and climate. ${ }^{3,4}$ Notably, there exist two distinct fates for the organic carbon from VOC oxidation, i.e., conversion to carbon dioxide $\left(\mathrm{CO}_{2}\right)$ or secondary organic aerosol (SOA), with drastically different atmospheric lifetimes of 5-200 years and about one week, respectively. ${ }^{2,3}$ Although long-lived $\mathrm{CO}_{2}$ is unequivocally linked to global warming, ${ }^{3}$ short-lived SOA often represents the dominant constituent of tropospheric fine aerosols. ${ }^{5-9}$ The products from VOC oxidation contribute to tropospheric aerosol loading via new particle formation, condensation/equilibrium partitioning, particle-phase reactions, and cloud processing. ${ }^{1,2,7-17}$ The enormous chemical complexity of VOC oxidation ${ }^{18-20}$ and the subsequent gas-to-particle conversion ${ }^{1,2}$ pose major challenges in assessing the atmospheric impacts for SOA., ${ }^{3,4}$ Atmospheric models have consistently underestimated SOA mass concentrations measured in field studies. ${ }^{7}$ Small $\alpha$-dicarbonyls, i.e., glyoxal (GL) and methylglyoxal (MG), are generated with high yields from photooxidation of aromatics ${ }^{1,2,18,19}$ and dike- tones ${ }^{20}$ relevant to motor vehicle and industrial sources and biogenic isoprene. ${ }^{21}$ The aqueous chemistry of glyoxal and methylglyoxal involving oxidation by the hydroxyl radical $(\mathrm{OH})$ has been shown as an important source of SOA via cloud processing. . $^{15,22-24}$

The conventional view is that methylglyoxal is less reactive than glyoxal because of the unreactive methyl substitution. ${ }^{25} \mathrm{~A}$ field-modeling study indicated that glyoxal from anthropogenic sources contributes to rapid and high SOA formation. ${ }^{26}$ Oligomerization of methylglyoxal was postulated based on the observation of high-molecular-weight polymers from $\mathrm{OH}$ oxidation of 1,3,5-trimethylbenzene (TMB) in an environmental chamber. ${ }^{27}$ However, experimental studies on nano- to sub-micrometer particles showed negligible size growth upon exposure to methylglyoxal vapor ${ }^{28-30}$ but large size growth upon exposure to glyoxal vapor under similar experimental

Received: November 29, 2020

Revised: February 23, 2021

Accepted: February 24, 2021

Published: March 16, 2021

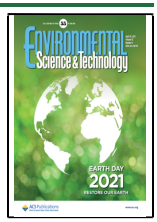




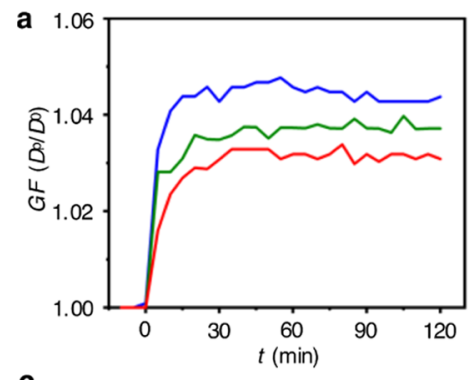

C
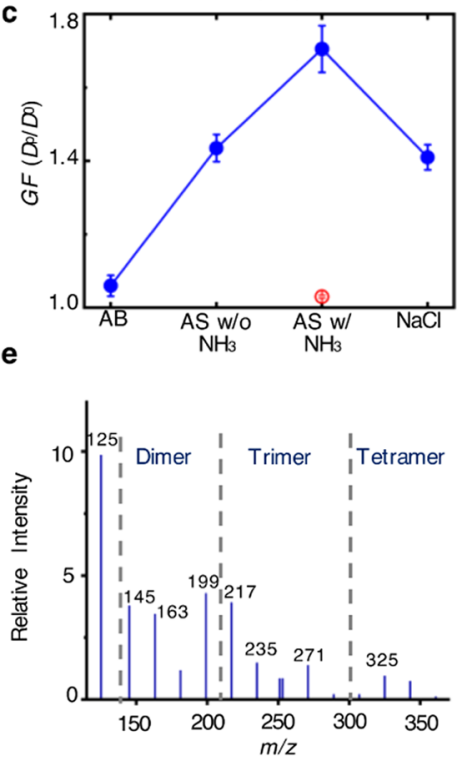

b

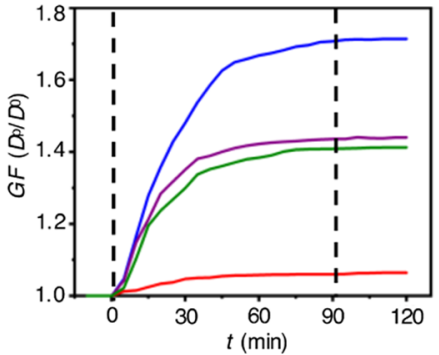

d

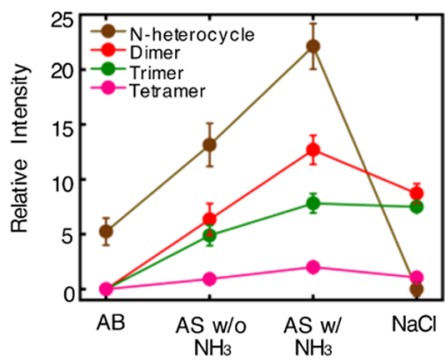

$\mathbf{f}$
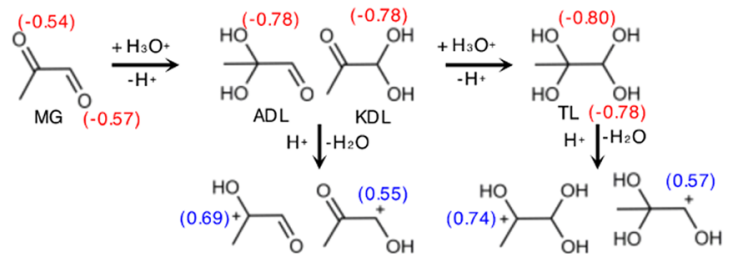



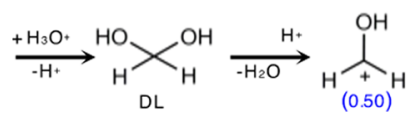

Figure 1. SOA growth from methylglyoxal. (a) Time-dependent growth factor $\left(\mathrm{GF}=D_{\mathrm{p}} / D_{0}\right)$ of AS seed particles exposed to methylglyoxal vapor continuously introduced to the chamber at steady-state concentrations of $5 \mathrm{ppm}$ (blue), $1 \mathrm{ppm}$ (green), and $500 \mathrm{ppb}$ (red). (b) Time-dependent GF of seed particles consisting of AS in the presence (blue) and absence (purple) of $19 \mathrm{ppb} \mathrm{NH}_{3}, \mathrm{NaCl}$ (green), and $\mathrm{AB}$ (red) exposed to the products from photochemical TMB-OH oxidation. The vertical dashed line at $t=0$ denotes the time for injection of methylglyoxal vapor or turning on the UV lights, and the vertical dashed line at $t=90 \mathrm{~min}$ denotes the time for obtaining GF. (c) Measured GF after 90 min of direct exposure to methylglyoxal vapor (red circle) and to the products from TMB-OH photochemical oxidation (blue circle). For experiments with exposure to the products of $\mathrm{OH}-\mathrm{TMB}$ oxidation, the initial concentrations of TMB and $\mathrm{H}_{2} \mathrm{O}_{2}$ were 1.8 and 114 ppm, respectively, and the steady-state concentration of methylglyoxal was $2 \mathrm{ppb}$. (d) Single-ion monitoring of particle-phase $n$-heterocycles at 83 and $125 \mathrm{~m} / z$, dimers at 145,163 , 181 , and $199 \mathrm{~m} / z$, trimers at $217,235,253,271$, and $289 \mathrm{~m} / z$, and tetramers at 307, 325, 343, 361, 379, 397, and $415 \mathrm{~m} / z$. Particles exposed to TMB$\mathrm{OH}$ photooxidation products were collected by TD-ID-CIMS after $30 \mathrm{~min}$ of exposure, and the collection time was $2 \mathrm{~h}$. (e) Mass spectral peaks of aerosol-phase products on $\mathrm{AS}$ in the presence of $\mathrm{NH}_{3}$. (f) Carbenium-ion formation from methylglyoxal (MG) and $\mathrm{CH} \mathrm{H}_{2} \mathrm{O}$. $\mathrm{ADL}, \mathrm{KDL}, \mathrm{TL}$, and DL denote aldehyde diol, ketone diol, tetrol, and diol, respectively. The numbers within parentheses denote the negative (red) or positive (blue) natural charge (in $e$ ). All experiments were performed at $298 \mathrm{~K}$ and $\mathrm{RH}=90 \%$. The uncertainty in measured GF corresponds to one standard deviation $(1 \sigma)$ of 6 measurements for direct methylglyoxal exposure, and all other uncertainties correspond to $1 \sigma$ of at least 3 measurements. Each GF measurement took 5 min, corresponding to each DMA scan.

conditions. $^{13,28-30}$ For example, significantly different growth factors of $(1.93 \pm 0.04)$ and $(1.01 \pm 0.01)$ were measured on sulfuric acid nanoparticles $(20 \mathrm{~nm})$ exposed to elevated glyoxal and methylglyoxal vapors (about 4 parts per million or ppm), respectively, at $20 \%$ relative humidity $(\mathrm{RH})$; the measured growth factor for glyoxal decreased with decreasing $\mathrm{RH}$ and size $(4-20 \mathrm{~nm}) .{ }^{29,30}$ On the other hand, comparable reactive uptake of glyoxal and methylglyoxal was measured on bulk sulfuric acid solution, ${ }^{32,33}$ and the difference in the uptake measurements between bulk solutions and nano/sub-micrometer particles implicated a profound interfacial effect. ${ }^{29,30}$ Also, surface browning was detected on ammonium/aminecontaining particles exposed to methylglyoxal despite negligible particle growth, ${ }^{31,35}$ and nitrogen-heterocycles ( $n$-heterocycles) were identified as light-absorbing brown carbon $(\mathrm{BrC})$ with low single-scattering albedo (SSA) in bulk mixtures consisting of methylglyoxal and amines. ${ }^{11}$ Moreover, previous studies hinged on measurements of direct exposure to high levels of glyoxal and methylglyoxal vapors, ${ }^{13,25-29}$ i.e., from hundred parts per billion ( $\mathrm{ppb}$ ) to ppm levels, or using bulk samples, ${ }^{30,31}$ for which their applicability to atmospheric conditions requires validation. Currently, available experimental results on the multiphase chemistry of $\alpha$-dicarbonyls are conflicting, ${ }^{13,25,27-35}$ casting doubt on their role in SOA formation.

\section{EXPERIMENTAL SECTION}

To elucidate the mechanisms leading to SOA and $\mathrm{BrC}$ formation from small $\alpha$-dicarbonyls, we performed laboratory measurements by exposing seed particles to glyoxal and methylglyoxal in the absence/presence of gaseous formaldehyde $\left(\mathrm{CH}_{2} \mathrm{O}\right)$ and ammonia $\left(\mathrm{NH}_{3}\right)$ using a $1 \mathrm{~m}^{3}$ reaction chamber $^{36,37}$ (see Methods and Figure S1 in the Supporting Information). Seed particles consisting of ammonium bisulfate $(\mathrm{AB})$, ammonium sulfate (AS) in the presence/absence of gaseous $\mathrm{NH}_{3}$, sodium chloride $(\mathrm{NaCl})$, or sucrose were chosen 

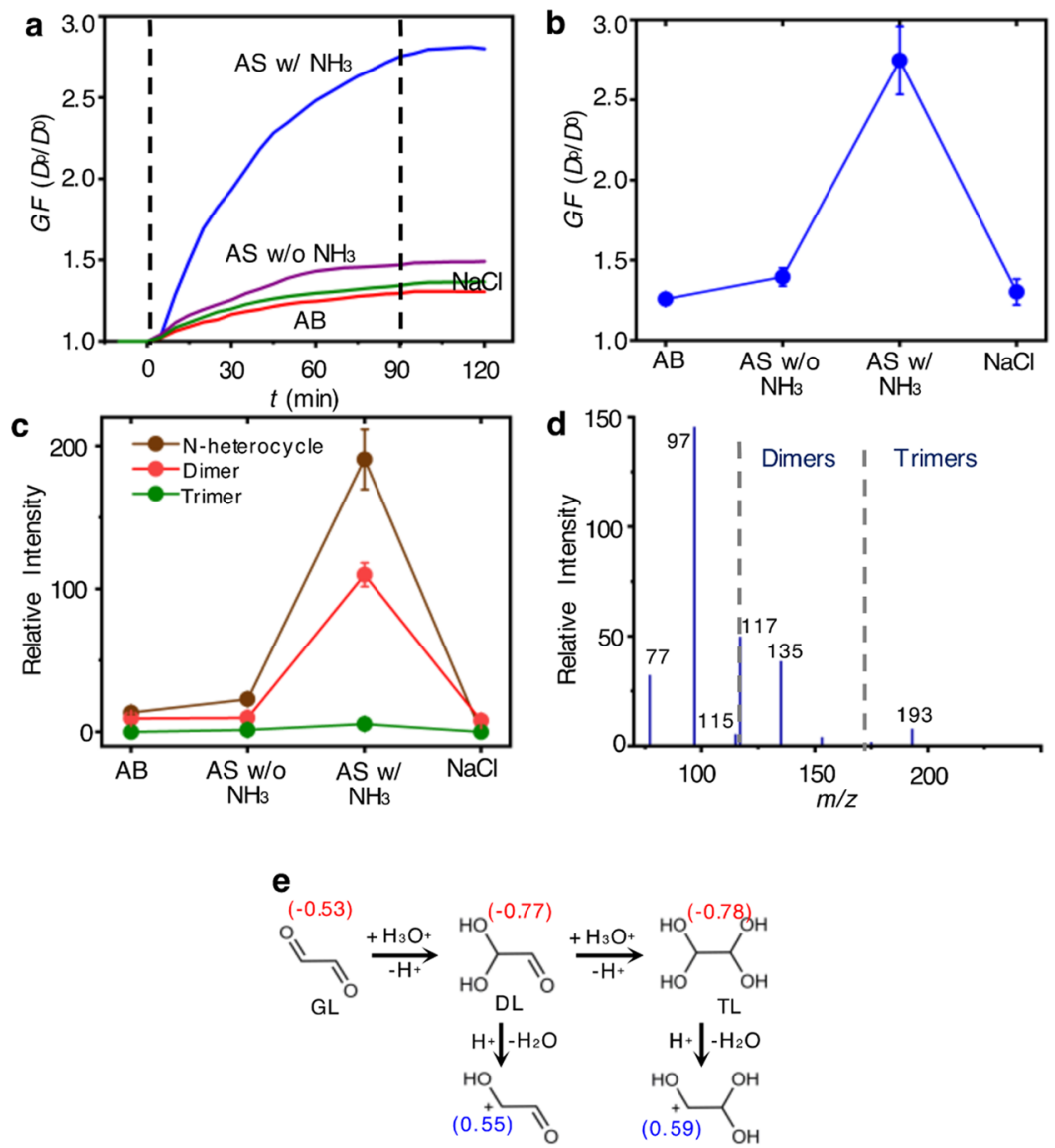

Figure 2. SOA growth from glyoxal. (a) Time-dependent GF for AS in the presence (blue) and absence (purple) of $19 \mathrm{ppb} \mathrm{NH}_{3}, \mathrm{NaCl}($ green), and $\mathrm{AB}$ (red) seed particles exposed directly to $9 \mathrm{ppb}$ glyoxal. The vertical dashed line at $t=0$ denotes the time of introducing glyoxal vapor, and the vertical dashed line at $t=90$ min denotes the time for obtaining GF. (b) Measured GF when directly exposed to 9 ppb glyoxal vapor at $t=90$ $\min$. (c) Single-ion monitoring of particle-phase $n$-heterocycles at 69,97 , and $115 \mathrm{~m} / z$, dimers at $117,136,153$, and $171 \mathrm{~m} / z$, and trimers at 175 ,

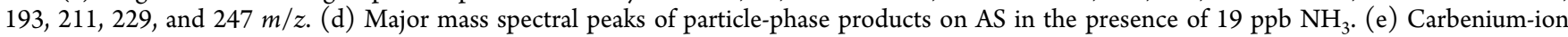
formation from glyoxal (GL). The numbers within parentheses denote the negative (red) or positive (blue) natural charge (in $e$ ). All experiments were performed at $298 \mathrm{~K}$ and $\mathrm{RH}=90 \%$. The error corresponds to $1 \sigma$ of at least 3 measurements.

to represent distinct acidity ${ }^{1,2}$ and interfacial charge separation. ${ }^{38}$ The size increase after exposure was measured by a differential mobility analyzer (DMA) and quantified by a growth factor, GF $=D_{\mathrm{p}} / D_{\mathrm{o}}$, where $D_{\mathrm{p}}$ is the diameter after exposure and $D_{\mathrm{o}}=100 \mathrm{~nm}$ is the initial diameter. The chemical composition of exposed particles was monitored by a thermal desorption-ion drift-chemical ionization mass spectrometer (TD-ID-CIMS). The optical properties (i.e., extinction and scattering) at $532 \mathrm{~nm}$ were measured using a cavity ring-down spectroscope and an integrating nephelometer. ${ }^{36,37}$

Three different approaches were employed to introduce methylglyoxal vapor to the chamber. First, purified methylglyoxal vapor was collected by a $1 \mathrm{~L}$ glass container, diluted in $\mathrm{N}_{2}$, and then flushed into the chamber. This approach was similar to previous studies, ${ }^{28-31}$ as seed particles were exposed to methylglyoxal vapor with an initial concentration of 100 , $500 \mathrm{ppb}, 1$, or $5 \mathrm{ppm}$. Alternatively, methylglyoxal vapor was continuously introduced into the chamber with a steady-state concentration of $500 \mathrm{ppb}, 1$, or $5 \mathrm{ppm}$ throughout the experiments. Additionally, experiments were performed with seed particles exposed to methylglyoxal produced from oxidation of $\mathrm{TMB}$ and $\mathrm{OH}$, which has a molar yield of $\sim 90 \%{ }^{27}$ Glyoxal vapor produced by heating glyoxal trimer dihydrate to $160{ }^{\circ} \mathrm{C}$ was continuously introduced to the chamber to reach a concentration of $9 \mathrm{ppb}$. The gaseous concentrations of glyoxal and methylglyoxal were measured using an ion drift-chemical ionization mass spectrometer with hydronium ions. ${ }^{32,33}$

\section{RESULTS AND DISCUSSION}

3.1. SOA and BrC Formation on Sub-Micrometer Aerosols. Exposure of AS particles to methylglyoxal vapor in a concentration range from $100 \mathrm{ppb}$ to $5 \mathrm{ppm}$ results in a small growth, with a GF of 1.03-1.04 (Figures 1a and S2). The temporal evolution of the GF shows that the size increase occurs only during the initial time, i.e., $t<10-20 \mathrm{~min}$ (each GF measurement took $5 \mathrm{~min}$ ). Figures $1 \mathrm{a}$ and $\mathrm{S} 2$ show that the measured GF increases slightly with an increasing methylglyoxal concentration and similar growth occurs in the experiments with methylglyoxal either introduced initially or continuously into the chamber, with the GF values of $(1.03 \pm$ 0.01 ) and $(1.04 \pm 0.01)$, respectively (Figure S2). The GF values measured in our work (Figures 1a and S2) are comparable to those of the previous experimental studies, ${ }^{26-29}$ which showed negligible particle growth upon exposure to methylglyoxal vapor (i.e., from $0.99 \pm 0.01$ to $1.02 \pm 0.01$ on sulfuric acid nanoparticles ${ }^{29}$ ). On the other hand, large particle growth occurs when methylglyoxal is produced from photooxidation of $\mathrm{TMB}$ by $\mathrm{OH}$. In the latter experiments, 
a

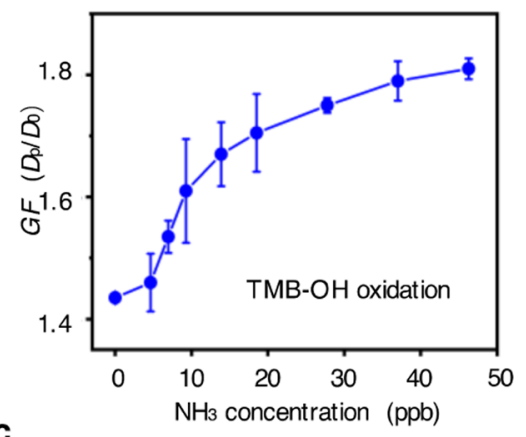

c

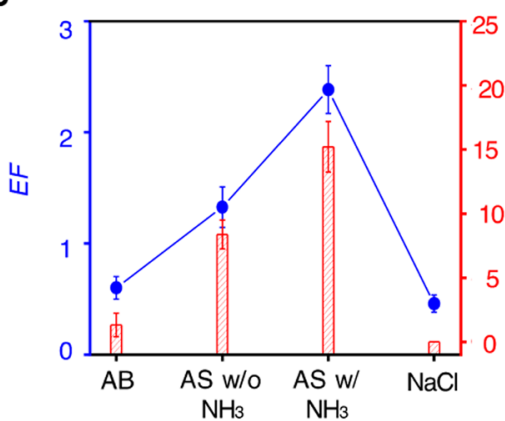

b

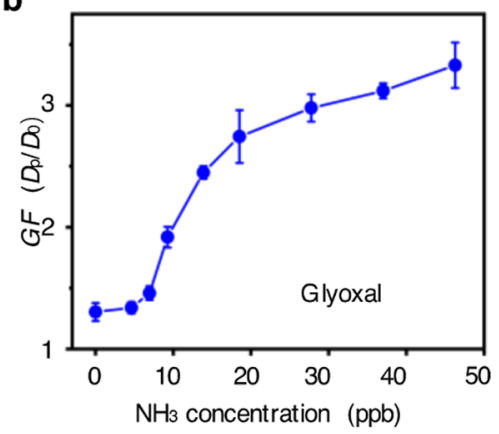

d

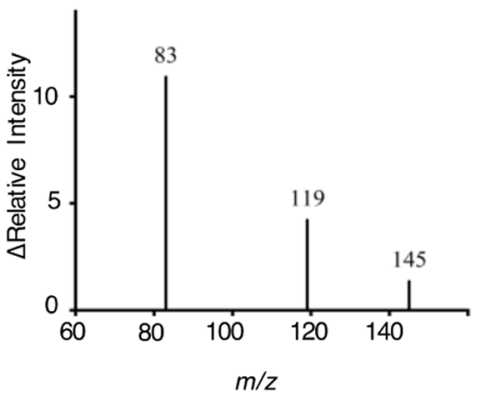

Figure 3. Synergetic oligomerization in the presence of $\mathrm{NH}_{3}$ and $\mathrm{CH}_{2} \mathrm{O}$. (a) Measured GF of AS particles exposed to TMB-OH oxidation products with varying $\mathrm{NH}_{3}(0-46 \mathrm{ppb})$. (b) Measured GF of AS particles exposed to glyoxal with varying $\mathrm{NH}_{3}(0-46 \mathrm{ppb})$. (c) Enhancement factor (EF) by addition of $\mathrm{CH}_{2} \mathrm{O}$ (blue), defined by $\left(D_{\mathrm{p}}{ }^{\prime 3}-D_{\mathrm{p}}{ }^{3}\right) / D_{\mathrm{o}}{ }^{3}$, where $D_{\mathrm{p}}{ }^{\prime}$ and $D_{\mathrm{p}}$ denote the particle diameters in the presence and absence of $31 \mathrm{ppb}$ $\mathrm{CH}_{2} \mathrm{O}$, respectively, and single-ion monitoring of the relative intensity change of the imidazole peak $(\mathrm{m} / z=83)$ on particles in the presence and absence of $\mathrm{CH}_{2} \mathrm{O}$ (red) for different seed particles exposed to TMB-OH oxidation products. (d) Change of the relative intensity of imidazole at $m$ / $z=83$, an intermediate at $m / z=119$, and methylglyoxal dimer at $m / z=145$ between the presence and absence of $\mathrm{CH}_{2} \mathrm{O}$ on seed particles exposed to the TMB-OH oxidation products. The error bar denotes $1 \sigma$ of 3 repeated measurements.

methylglyoxal was continuously produced from TMB-OH oxidation, resulting in a steady-state mixing ratio of about 2 $\mathrm{ppb}$ (Figure 1b,c) that closely replicates the atmospheric conditions. ${ }^{1,2}$ Figure $1 \mathrm{~b}$ shows gradual and continuous particle growth throughout the experiments on different seed particles. The measured GF is dependent on seed particles, and the highest GF of $1.70 \pm 0.06$ corresponds to AS particles in the presence of $19 \mathrm{ppb} \mathrm{NH}$ (Figure $1 \mathrm{~b}, \mathrm{c}$ ). Also, there is a weak dependence of GF on RH from 50 to $90 \%$ (Figure S3a). Measurements of chemical compositions of the exposed particles by TD-ID-CIMS reveal that the size increase results dominantly from formation of oligomers and $n$-heterocycles (Figures 1d, S4a and S5a, and Tables S1 and S2). Both oligomers and $n$-heterocycles are detected on $\mathrm{AB}$ and $\mathrm{AS}$, whereas only oligomeric products are identified on $\mathrm{NaCl}$. Formation of oligomers and $n$-heterocycles varies with seed particles similarly as GF (Figure 1c) and decreases from $n$ heterocycles (except for $\mathrm{NaCl}$ ), dimers, trimers, to tetramers (Figure 1e). The mechanism for the aqueous reactions involves the methylglyoxal carbenium ions as the key intermediates (Figure 1f), which subsequently undergo nucleophilic addition to yield oligomers and $n$-heterocycles. ${ }^{39}$

We conducted experiments by exposing seed particles to glyoxal vapor in the presence/absence of $\mathrm{NH}_{3}$ (Figure 2). In contrast to direct exposure to methylglyoxal vapor, continuous and significant particle growth occurs upon exposure to glyoxal vapor at a mixing ratio of $9 \mathrm{ppb}$ (Figure 2a,b). Exposure of AS particles to glyoxal in the presence of $19 \mathrm{ppb} \mathrm{NH}_{3}$ exhibits the highest GF of $2.75 \pm 0.07$ at $90 \mathrm{~min}$, while smaller GF (1.3 to 1.5) occurs for $\mathrm{AB}, \mathrm{NaCl}$, and $\mathrm{AS}$ in the absence of $\mathrm{NH}_{3}$ (Figure 2a,b). Also, the measured GF exhibits a weak dependence on $\mathrm{RH}$ from 50 to $90 \%$ (Figure S3b). Chemical speciation of the aerosol-phase products by TD-ID-CIMS indicates the highest intensities for dimers and $n$-heterocycles, lower intensities for trimers, and no measurable tetramers. The maximal intensities for dimers and $n$-heterocycles also correspond to AS with $\mathrm{NH}_{3}$ (Figures $2 \mathrm{c}, \mathrm{d}, \mathrm{S} 4 \mathrm{~b}$ and $\mathrm{S} 5 \mathrm{~b}$, and Tables S1 and S2). Similarly, formation of oligomers and $n$ heterocycles involves the glyoxal carbenium ions as the key intermediates (Figure 2e). ${ }^{39}$ Our measured size growth of seed particles exposed to glyoxal is consistent with the available experimental results. ${ }^{27-29}$ For comparison, a previous study measured a GF value of $1.93 \pm 0.04$ on $20 \mathrm{~nm}$ sulfuric acid nanoparticles exposed to glyoxal at $20 \% \mathrm{RH}$ and identified the isomeric products of dimers, trimers, tetramers, and pentamers. $^{28}$

Additional experiments of glyoxal and methylglyoxal uptake were performed on AS particles by varying $\mathrm{NH}_{3}$ from 0 to 46 ppb. The measured GF for both glyoxal and methylglyoxal increases monotonically with increasing $\mathrm{NH}_{3}$ (Figure 3a,b). The significant particle growth in the presence of $\mathrm{NH}_{3}$ contrasts with a previous experimental study, ${ }^{30}$ showing negligible growth of sulfuric acid nanoparticles exposed to increased gaseous $\mathrm{NH}_{3}$ (with only acid-base reaction). The increase in GF with $\mathrm{NH}_{3}$ is explained by inhibited $\mathrm{NH}_{3}$ evaporation from AS and the reaction of $\mathrm{NH}_{3}$ with methylglyoxal/glyoxal to yield nonvolatile $n$-heterocycles (Figure S6); the latter is confirmed from the simultaneous increases in GF and the intensities of particle-phase nheterocycles (Figures $1 \mathrm{c}$ and $2 \mathrm{c}$ ).

We also performed experiments to examine the effects of $\mathrm{CH}_{2} \mathrm{O}$ on particle growth from $\alpha$-dicarbonyls. Although 
a

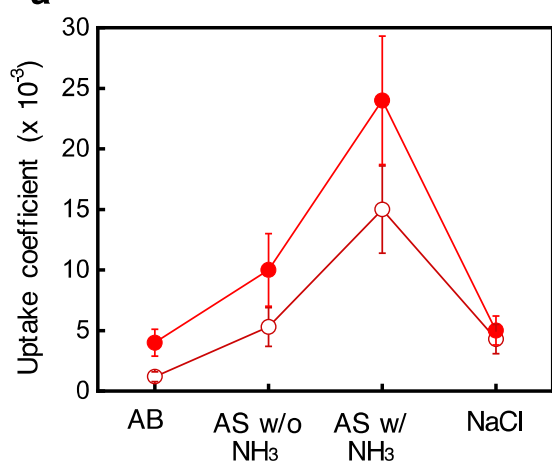

b

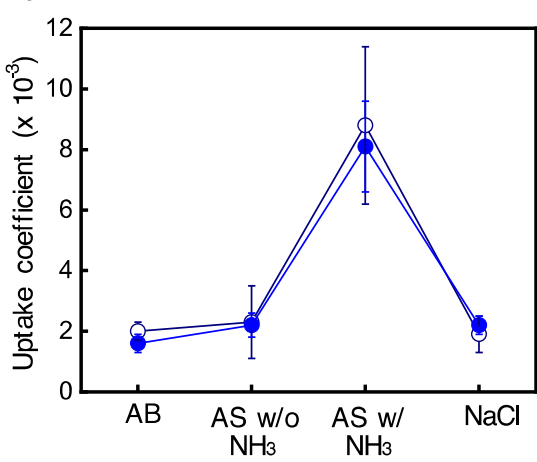

C

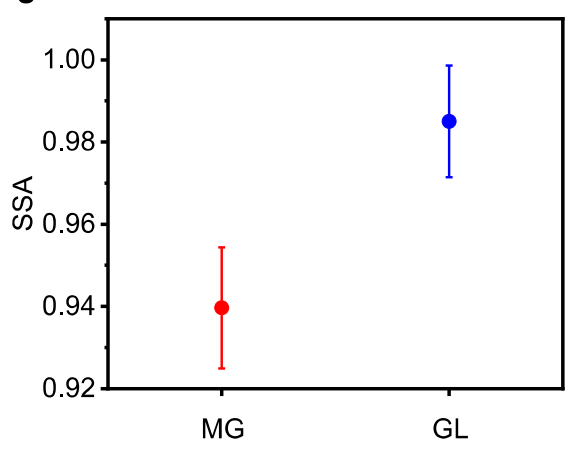

Figure 4. Distinct reactivity and light absorption between methylglyoxal and glyoxal. (a) Uptake coefficient for methylglyoxal on different seed particles with $31 \mathrm{ppb} \mathrm{CH}_{2} \mathrm{O}$ (red solid circles) and without $\mathrm{CH}_{2} \mathrm{O}$ (red open circles). (b) Uptake coefficient for glyoxal on different seed particles

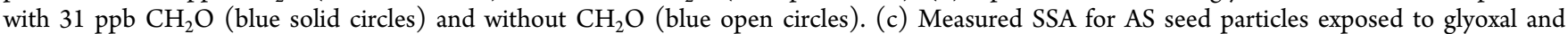
methylglyoxal with $19 \mathrm{ppb} \mathrm{NH}_{3}$. The error bar denotes $1 \sigma$ of 3 repeated measurements.

exposure of seed particles to $\mathrm{CH}_{2} \mathrm{O}$ vapor in the absence of glyoxal or methylglyoxal results in no measurable growth (Figure S7), addition of $\mathrm{CH}_{2} \mathrm{O}$ considerably increases the particle growth from TMB-OH oxidation (Figure 3c), as determined by an enhancement factor, $\mathrm{EF}=\left(D_{\mathrm{p}}{ }^{\prime 3}-D_{\mathrm{p}}{ }^{3}\right) / D_{\mathrm{o}}{ }^{3}$, where $D_{\mathrm{p}}{ }^{\prime}$ and $D_{\mathrm{p}}$ are the particle diameters in the presence and absence of $\mathrm{CH}_{2} \mathrm{O}$, respectively. The EF varies with seed particles, reaching a maximum value of $2.4 \pm 0.2$ for AS with $\mathrm{NH}_{3}$. Analysis of particle composition reveals that the enhancement is attributed to the simplest $n$-heterocycleimidazole products $(m / z=83)$, along with an intermediate $(m / z=119)$ and the smallest dimers $(m / z=145)$ (Figure $3 c, d)$. On the other hand, addition of $\mathrm{CH}_{2} \mathrm{O}$ results in a slight decrease of GF for exposure to glyoxal vapor (Figure S8), and no imidazole formation is observed with $\mathrm{CH}_{2} \mathrm{O}$ addition.

Using the measured GF, we derived the uptake coefficients $(\gamma)$ for methylglyoxal and glyoxal, which are dependent on seed particles and the presence of $\mathrm{NH}_{3}$ and $\mathrm{CH}_{2} \mathrm{O}$ (see Methods, Figure 4a,b, and Table S3). The measured uptake coefficients are higher for methylglyoxal than glyoxal: the $\gamma$ values on AS seed particles in the presence of $\mathrm{NH}_{3}$ and $\mathrm{CH}_{2} \mathrm{O}$ are $(2.4 \pm 0.5) \times 10^{-2}$ and $(8.1 \pm 1.5) \times 10^{-3}$ for methylglyoxal and glyoxal, respectively. We also measured light extinction and scattering at a wavelength of $532 \mathrm{~nm}$ for sub-micrometer particles after exposure to methylglyoxal/ glyoxal for $90 \mathrm{~min}$. The measured SSA of $0.940 \pm 0.015$ for methylglyoxal is lower than that of $0.985 \pm 0.013$ for glyoxal (Figure 4c), consistent with a previous bulk measurement of stronger light absorption for methylglyoxal than glyoxal from the reactions with amines in bulk solutions. ${ }^{11}$

3.2. Carbenium Ion-Mediated Nucleophilic Addition. The particle growth from glyoxal and methylglyoxal is regulated by complex aerosol processes (Figure 5), including interfacial interaction as well as liquid-phase diffusion and reaction. ${ }^{1,2,40}$ We performed molecular dynamics simulations to evaluate the interfacial interaction of methylglyoxal. A significant decrease in the free energy $\left(\sim 4 \mathrm{kcal} \mathrm{mol}^{-1}\right)$ occurs when methylglyoxal approaches the air-water interface, indicating a thermodynamically favorable process (Figure 5a). Analysis of the orientation of methylglyoxal reveals that the interfacial interaction is initiated by the carbonyl O-atom, which possesses a prominent negatively charged Natural Bond Orbital (NBO) characteristic $(-0.57 e)$. Previous experimental studies demonstrated that net charge separation arises from ion distributions at the air-water interface on bulk solutions: the
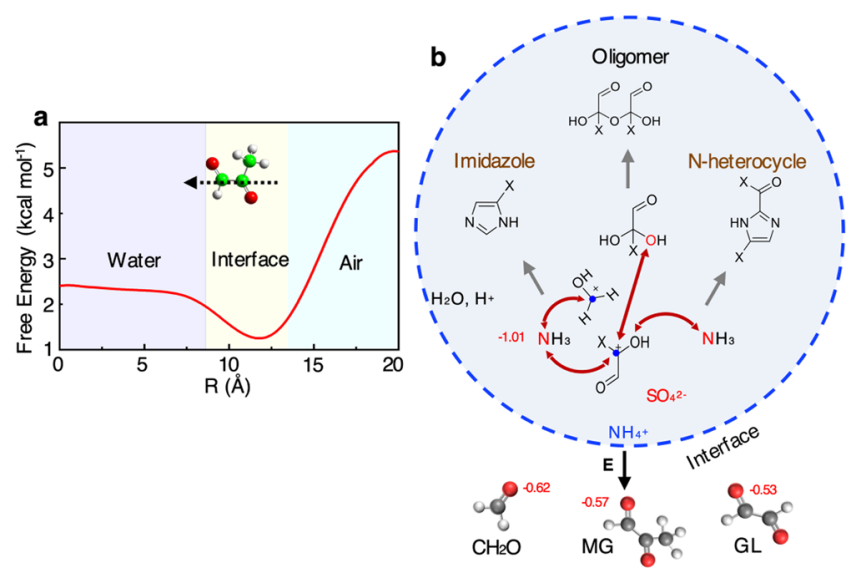

Figure 5. Carbenium ion-mediated, interfacial electric field-enhanced, and synergetic SOA and $\mathrm{BrC}$ formation. (a) Molecular dynamics simulation of the free energy surface when methylglyoxal approaches the air-water interface. The dashed arrow marks the orientation of methylglyoxal at the interface. (b) Interfacial and cationic enhancement of aerosol formation from carbonyl and hydroxyl organics on AS particles. The numbers denote negative (red) or positive (blue) partial charges in $e$ for interfacial electronic attraction or nucleophilic addition. The black arrow with the letter E marks a positive electric field (pointing away from the interface) induced from net charge separation of $\mathrm{NH}_{4}^{+}$and $\mathrm{SO}_{4}{ }^{2-}$ distributions at the air-water interface. ${ }^{38}$ The black-dashed arrows connect the sites for nucleophilic addition. In the molecular structures, $\mathrm{X}=\mathrm{H}$ or $\mathrm{CH}_{3}$ corresponds to glyoxal- or methylglyoxal-derived products, respectively, and the blue dots represent the positively charged carbon atoms of the carbenium ions.

electric field is strongly positive for AS, negligible for $\mathrm{AB}$, and slightly negative for $\mathrm{NaCl} .{ }^{38}$ Net charge separation to form the interfacial electric field is likely increased on sub-micrometer aerosols because of high-ionic strength. ${ }^{41}$ The interfacial electric attraction on AS is more pronounced for methylglyoxal and $\mathrm{CH}_{2} \mathrm{O}$ because of their larger dipole moments $(1.06 \mathrm{D}$ for methylglyoxal and $3.23 \mathrm{D}$ for $\mathrm{CH}_{2} \mathrm{O}$ ) and more negative natural charges on the carbonyl O-atom $(-0.57 e$ for methylglyoxal and $-0.62 e$ for $\mathrm{CH}_{2} \mathrm{O}$ ) (Figures if and 5). On the other hand, interfacial attraction on AS is weaker for glyoxal because of the absence of the dipole moment and smaller negatively charge carbonyl $\mathrm{O}$-atom $(-0.53 e)$ (Figures $2 \mathrm{e}$ and 5$)$. Hence, the ion-induced dipole interaction occurs in a short range for glyoxal but in a long range for methylglyoxal. 
A recent theoretical study showed a smaller decrease in the free energy ( $\left.\sim 3 \mathrm{kcal} \mathrm{mol}^{-1}\right)$ for glyoxal than for methylglyoxal $(\sim 4$ $\mathrm{kcal} \mathrm{mol}^{-1}$ in Figure 5a), when approaching the air-water interface. $^{42}$

An acid-catalyzed mechanism was speculated for multiphase reactions of organic carbonyls (including glyoxal). ${ }^{13}$ Measurements of methylglyoxal and glyoxal on bulk sulfuric acid solutions and of glyoxal on sulfuric acid nanoparticles indicated reduced uptake with acidity, ${ }^{29,30,32,33}$ invoking hydration-based oligomerization. However, hydration for glyoxal and methylglyoxal to form diols/tetrols is kinetically unfeasible (with an activation energy of $44 \mathrm{kcal} \mathrm{mol}^{-1}$ for methylglyoxal), and oligomerization is mediated by carbenium ions, ${ }^{39}$ which are formed from protonation, hydration, and deprotonation of dicarbonyls (Figures 1e and 2e). Formation of oligomers and $n$-heterocycles includes nucleophilic addition to the carbenium cation by the negative hydroxyl O-atom $(-0.77$ to $-0.80 e)$ of diols/tetrols or the negative $\mathrm{N}$-atom $(-1.01 e)$ of $\mathrm{NH}_{3}$, respectively (Figures 1e, 2e, and S5). Each step of the cationic oligomerization proceeds without an activation barrier and is enhanced by ion-dipole interaction. ${ }^{39}$ Carbenium ions are broadly produced from carbonyls, ${ }^{39,43}$ as is also reflected from the large particle growth and formation of imidazole products in the presence of $\mathrm{CH}_{2} \mathrm{O}$ (Figure $3 \mathrm{c}, \mathrm{d}$ ). Compared to glyoxal and methylglyoxal, the $\mathrm{O}$-atom in $\mathrm{CH}_{2} \mathrm{O}$ has the strongest negative charge, while the $\mathrm{C}$-atom on the ${ }^{+} \mathrm{CH}_{2} \mathrm{OH}$ carbenium ion has the weakest positive charge $(0.50 e)$, indicating facile protonation but inefficient nucleophilic addition (Figure $5 \mathrm{~b}$ ). The positive natural charges $(0.55 e$ and $0.59 e)$ on the $\mathrm{C}$-atoms of the glyoxal carbenium ions are slightly larger than that of the formaldehyde carbenium ion $(0.50 e)$ but are smaller than those of the methylglyoxal carbenium ions $(0.69 e$ and $0.74 e$ ) with the methyl substitution (Figures $1 \mathrm{e}$ and 2e). In the presence of $\mathrm{CH}_{2} \mathrm{O}$, there exists a competition between the formaldehyde carbenium ion $\left({ }^{+} \mathrm{CH}_{2} \mathrm{OH}\right)$ and glyoxal carbenium ions in the reactions with diols, tetrols, or $\mathrm{NH}_{3}$; the former yields smaller, more volatile oligomers, leading to inhibited particle growth (Figures $4 \mathrm{~b}$ and S8). In contrast, methylglyoxal carbenium ions react efficiently with $\mathrm{NH}_{3}$ to form imines, which subsequently react with the $\mathrm{CH}_{2} \mathrm{O}$ carbenium ions to form nonvolatile imidazole products, explaining the higher growth factors and larger uptake coefficients for methylglyoxal in the presence of $\mathrm{CH}_{2} \mathrm{O}$ (Figures 3c,d and $4 \mathrm{a}$ ). To further evaluate the generality of the cationic mechanism, we performed additional experiments using seed particles consisting of sucrose as a surrogate for hydroxycarbonyls (Figure S9). Significant size growth occurs upon exposure of sucrose particles to TMB-OH oxidation, with comparable GF to that measured on AS with $\mathrm{NH}_{3}$. Composition analysis reveals the dominant presence of dimers and sucrose. Sucrose seed particles are neutral and do not involve interfacial charge separation, but the presence of the hydroxy functional groups in sucrose provides the abundant sites for nucleophilic addition to the carbenium ions for oligomerization. Chemical speciation of the particle-phase composition shows much stronger dimer peaks $(m / z=145$, $163,199)$ and sucrose peak $(m / z=325)$ than that on AS particles, indicating the dominant formation of sucrosemethylglyoxal or sucrose-dimer adducts. In our TD-ID-CIMS measurements, the oligomeric adducts likely decompose to yield dimer and sucrose molecules.

The carbenium ion-mediated oligomerization ${ }^{39}$ is distinct from those previously proposed involving an acid catalyst or hydration. $^{13,32}$ Although protonation is favored under acidic conditions, high acidity inhibits hydration and deprotonation to form diols/tetrols and to propagate oligomerization, ${ }^{39}$ explaining the highest particle growth under moderate acidic condition (i.e., on $\mathrm{AS} \mathrm{w} / \mathrm{NH}_{3}$ ). The oligomerization pathway occurs in a wide range of acidity and $\mathrm{RH}$, as evident from significant GF and detection of the oligomeric products on all seed particles (i.e., $\mathrm{pH}$ from 7 for $\mathrm{NaCl}$ and sucrose to -0.5 for $\mathrm{AB}) .{ }^{2}$ On the other hand, aqueous reactions to yield oligomers and $n$-heterocycles are likely suppressed at low $\mathrm{RH}$ (i.e., below the efflorescent point), because of hindered protonation, hydration, and deprotonation. ${ }^{44}$ The multiphase reactions of methylglyoxal/glyoxal increase the particle size by a factor of up to 3 (or the mass by a factor of up to 30) on AS, depending on the abundance of organics or $\mathrm{NH}_{3}$. Our observed dependencies of GF and particle-phase product distributions on different seed particles (Figures 1 and 2) are explained by the combined effects of interfacial attraction and liquid-phase reactions. The largest GF and highest formation of nonvolatile products on AS particles are attributed to the strongest interfacial attraction $^{38}$ and the most efficient nucleophilic addition involving the carbenium ions. ${ }^{39}$ Also, the mechanism established in our work is distinct from previous results of salting-in and salting-out for glyoxal and methylglyoxal, respectively. ${ }^{45}$ Our measurements of particle chemical compositions show the dominant formation of oligomers and n-heterocycles from methylglyoxal and glyoxal but an absence of other ingredients associated with salting-in and salting-out. In addition, a catalytic role of $\mathrm{NH}_{4}{ }^{+}$was proposed for oligomerization of methylglyoxal, ${ }^{46}$ in contrast to the mechanism involving nucleophilic addition of the carbenium ions by negatively charged ammonia to form n-heterocycles (Figure S5).

3.3. Surface- vs Volume-Limited Oligomerization. A major distinction in direct exposure of AS seed particles between methylglyoxal and glyoxal vapors lies in significantly different particle growth in our present experiments as well as in previous studies, ${ }^{29-31}$ i.e., a negligibly small growth for methylglyoxal but a large growth for glyoxal (Figures $1 \mathrm{a}, \mathrm{b}$ and $2 \mathrm{a}, \mathrm{b})$. This disparity is attributed to surface- versus volumelimited reactions on sub-micrometer particles between the two species. Interfacial attraction, protonation, and nucleophilic addition occur more efficiently for methylglyoxal than glyoxal on AS particles (Figure 5). The negative polarity of the carbonyl $\mathrm{O}$-atom is crucial to providing the protonation site. The methyl substituent increases the carbonyl bond polarization through the inductive electron donating and hyperconjugation effects, ${ }^{11,39}$ as reflected by the more negatively charged $\mathrm{O}$-atom in methylglyoxal than glyoxal (Figures 1e and $5 b)$. In addition, the positive charge on the carbenium ion in methylglyoxal is stronger with methyl substitution, favoring more efficient nucleophilic addition. For glyoxal and methylglyoxal, there is a significant decrease (by a factor of 2-3) in the liquid-phase diffusion coefficients from monomers to trimers (Table S4). The small growth of sub-micrometer particles exposed directly to methylglyoxal vapor (Figures 1a and S2) is explained by surface-limited aqueous reactions (Figure S10a). Efficient formation of oligomers and $n$ heterocycles under elevated methylglyoxal results in rapid oligomerization on the surface and subsequently reduced liquid-phase diffusion. The formation of surface coating is evident from the temporal evolution in the particle growth, i.e., an initial and small GF of 1.03-1.04 (corresponding to a 
coating thickness of $1.5-2.0 \mathrm{~nm}$ ), when AS particles are directly exposed to methylglyoxal of $100 \mathrm{ppb}$ to $5 \mathrm{ppm}$ (Figures $1 \mathrm{a}$ and S2). The surface coating consisting of nonvolatile products is hydrophobic ${ }^{47}$ and viscous, prohibiting subsequent particle growth and leading to surface-limited reactions. Similarly, surface coating by rapid oligomerization likely explains the negligible size growth of seed particles exposed to increased levels of methylglyoxal vapor (i.e., several hundred $\mathrm{ppb}$ to $\mathrm{ppm}$ levels) in previous studies. ${ }^{28-30}$ On the other hand, formation of a hydrophobic coating is avoided with continuous methylglyoxal production from TMB-OH oxidation at a lower concentration $(\sim 2 \mathrm{ppb})$, as reflected by the continuous and significant particle growth (Figures 1 and S2). Our results of continuous and significant particle growth for methylglyoxal produced from TMB-OH oxidation are consistent with previous measurements of irreversible methylglyoxal uptake on bulk solutions ${ }^{32}$ and formation of oligomeric products from the TMB-OH oxidation experiment. ${ }^{27}$ Note that the production of methylglyoxal from TMB-OH oxidation closely mimics that in the atmosphere. ${ }^{1}$ Although methylglyoxal represents the dominant product with a molar yield of $90 \%$ from TMB-OH oxidation, ${ }^{27}$ other oxidation products may play a secondary role in the measured particle growth. Our TD-ID-CIMS measurements confirm that oligomers and $n$ heterocycles from methylglyoxal, $\mathrm{NH}_{3}$, and $\mathrm{CH}_{2} \mathrm{O}$ account for the dominant particle-phase products, contributing up to $70 \%$ of the measured total intensities (Figure 1e and Table S3). In contrast, oligomerization from glyoxal is clearly volumelimited, as evident from the continuous and significant particle growth in our present experiments as well as in previous studies. $^{28-31}$ Inefficient interfacial attraction, protonation, and nucleophilic addition for glyoxal results in less-efficient oligomerization, leading to the absence of surface coating over a wide concentration range (i.e., $9 \mathrm{ppb}$ in our present experiment and from several hundred $\mathrm{ppb}$ to $\mathrm{ppm}$ levels in previous studies ${ }^{27-29}$ ). Hence, the considerable differences in aerosol growth and light absorption between methylglyoxal and glyoxal are explainable by surface- or volume-limited reactions, which are governed by their reactivity and gaseous concentrations. Efficient (inefficient) oligomerization for methylglyoxal (glyoxal) results in the formation (absence) of surface coating because of rapid (slow) liquid-phase diffusion and volume-limited (surface-limited) reactions, reconciling the discrepancy in measured particle growth in our present experiments and in previous studies (Figure S10b). ${ }^{27-31}$

3.4. Global Perspective for SOA and BrC. Large amounts of oxygenated organics consisting of carbonyl and hydroxyl functional groups are produced from VOC oxidation $^{1,2,18-21}$ (Figure S11a), with predicted global budgets of $223 \pm 34 \mathrm{Tg} \mathrm{a}^{-1}$ for methylglyoxal and glyoxal and $1466 \pm$ $189 \mathrm{Tg} \mathrm{a}^{-1}$ for $\mathrm{CH}_{2} \mathrm{O}$ (Table S5). Also, a major fraction of multifunctional hydroxycarbonyls is produced from biogenic VOC oxidation, e.g., $108 \pm 13 \mathrm{Tg} \mathrm{a}^{-1}$ for C4-C5 hydroxycarbonyls from isoprene oxidation alone. ${ }^{48}$ In comparison, a global budget of $69 \pm 13 \mathrm{Tg} \mathrm{a}^{-1}$ for $\mathrm{NH}_{3}$ is predicted. ${ }^{2}$ Currently, many oxygenated organics are not considered in atmospheric models for $\mathrm{SOA}$ and $\mathrm{BrC}$ formation because of their high volatility. ${ }^{1,2,7-10}$

Our results demonstrate unequivocally that carbonyls (glyoxal/methylglyoxal, $\mathrm{CH}_{2} \mathrm{O}$, hydroxycarbonyls) contribute significantly to SOA growth on sub-micrometer particles under atmospherically relevant conditions. The mechanism established in the present work explains the ubiquitous coexistence between SOA and AS from global measurements ${ }^{5}$ as well as during severe haze formation. ${ }^{6,41,49,50}$ For example, field measurements showed that the mass fractions of SOA and AS at urban locations worldwide are $(29.5 \pm 11.7)$ and $(35.0 \pm$ $11.7) \%$ (Figure S12a and Table S6), respectively, representing the two most abundant ingredients in secondary aerosols. ${ }^{5}$ Also, severe haze formation in China is consistently characterized by concurrent increases in the mass concentrations of SOA and AS (Figure S12b,c). ${ }^{1,6,41,49,50}$ In particular, explosive secondary aerosol growth was observed under polluted urban conditions, which is dominated by SOA formation. $^{51}$ These field measurements are consistent with synergetic aerosol formation from interacting carbonyls and $\mathrm{NH}_{3} /$ AS. Specifically, hygroscopic AS aerosols promote SOA formation by inducing interfacial attraction ${ }^{38}$ and protonation for carbonyls and nucleophilic addition to form nonvolatile oligomers and $n$-heterocycles. ${ }^{39}$ Also, the multiphase chemistry represents an important pathway for sulfate formation from anthropogenic sulfur dioxide $\left(\mathrm{SO}_{2}\right)$ emissions, ${ }^{1,2}$ and an increasing organic content enhances aqueous sulfate production. ${ }^{41,49-51}$ Furthermore, the synergetic aerosol formation involving carbonyls and $\mathrm{NH}_{3} / \mathrm{AS}$ implies a larger-thanrecognized biogenic-anthropogenic interaction, ${ }^{17,52}$ which is critical to assessing anthropogenic influences on varying atmospheric compositions and radiative forcing. ${ }^{1-4}$ Our experimental results show a 30 -fold increase in the SOA mass growth on AS particles, implying that changes in anthropogenic $\left(\mathrm{NH}_{3}\right.$ and $\left.\mathrm{SO}_{2}\right)$ emissions inevitably amplify the global SOA budget, which is dominated by biogenic sources. ${ }^{2,3}$ Currently, the total global SOA and AS budgets are estimated to be $112 \pm 40$ and $150 \pm 26 \mathrm{Tg} \mathrm{a}^{-1}$, respectively (Figure S11b and Table S5). Our measured uptake coefficients for glyoxal and methylglyoxal, which account for the carbenium ion-mediated nucleophilic addition, interfacial electric field attraction, and organic-inorganic interaction, are applicable to atmospheric models. Future studies are necessary to reassess secondary aerosol formation from the interaction between natural (biogenic VOC) and anthropogenic $\left(\mathrm{NH}_{3}\right.$ and $\left.\mathrm{SO}_{2}\right)$ emissions, by implementing the fundamental chemical mechanisms in global chemical transport models. 3,21

\section{ATMOSPHERIC IMPLICATIONS}

Our work provides direct experimental evidence for carbenium ion-mediated, interface electric field-enhanced, and synergetic oligomerization involving ubiquitous glyoxal, methylglyoxal, $\mathrm{CH}_{2} \mathrm{O}$, hydroxycarbonyls, $\mathrm{NH}_{3}$, and ammonium sulfate. We show that methylglyoxal is more reactive than glyoxal because of (i) significantly more efficient growth and larger uptake coefficient on seed particles under atmospherically relevant concentrations, (ii) lower SSA on AS seed particles, (iii) higher formation of imidazole in the presence of $\mathrm{CH}_{2} \mathrm{O}$, and (iv) more rapid formation of surface coating for methylglyoxal than glyoxal. The largest size growth on AS seed particles with $\mathrm{NH}_{3}$ corroborates the mechanisms of interfacial electric fieldenhanced $^{38}$ and carbenium ion-mediated ${ }^{39}$ oligomerization. Our findings resolve an outstanding discrepancy concerning the multiphase chemistry of glyoxal and methylglyoxal in previous experimental studies, ${ }^{13,27-35}$ which are attributable to surface- versus volume-limited reactions. The multiphase chemistry leading to SOA and $\mathrm{BrC}$ formation is dependent on the reactivity and gaseous concentrations of the aerosol precursors as well as the physicochemical properties of seed 
particles (i.e., size, $\mathrm{pH}$, phase state, chemical composition, etc.), highlighting the necessity to closely mimic the atmospheric conditions in future laboratory studies to investigate aerosol chemistry. ${ }^{53,54}$

Aerosol formation involving atmospherically abundant carbonyls (i.e., glyoxal/methylglyoxal, $\mathrm{CH}_{2} \mathrm{O}$, hydroxycarbonyls) and ammonia/ammonium sulfate established here occurs widely on aqueous aerosols and cloud/fog droplets under typically tropospheric conditions, ${ }^{1,2}$ providing an explanation for ubiquitous coexistence between SOA and AS from global aerosol measurements ${ }^{5}$ and during severe haze formation in Asia. ${ }^{1,6,41,49-51}$ Recognition of this aerosol formation mechanism from natural and anthropogenic emissions also implies larger-than-expected biogenic-anthropogenic interaction ${ }^{17,52}$ and a major missing source for $\mathrm{SOA}$ and $\mathrm{BrC}$ formation on urban, regional, and global scales.

\section{ASSOCIATED CONTENT}

\section{SI Supporting Information}

The Supporting Information is available free of charge at https://pubs.acs.org/doi/10.1021/acs.est.0c08066.

Methods; particle growth measurement; estimation of vapor concentrations; determination of uptake coefficient for methylglyoxal/glyoxal; optical properties; molecular dynamic simulations (PDF)

\section{AUTHOR INFORMATION}

\section{Corresponding Authors}

Yuemeng Ji - Guangzhou Key Laboratory of Environmental Catalysis and Pollution Control, School of Environmental Science and Engineering, Institute of Environmental Health and Pollution Control, Guangdong University of Technology, Guangzhou 510006, China; Email: jiym@gdut.edu.cn

Renyi Zhang - Department of Atmospheric Sciences, Texas A\&M University, College Station, Texas 77843, United States; 다이.org/0000-0001-8708-3862; Email: renyizhang@tamu.edu

\section{Authors}

Yixin Li - Department of Chemistry, Texas A\&M University, College Station, Texas 77843, United States

Jiayun Zhao - Department of Chemistry, Texas A\&M University, College Station, Texas 77843, United States

Yuan Wang - Division of Geological and Planetary Sciences, California Institute of Technology, Pasadena, California 91125, United States

Qiuju Shi - Guangzhou Key Laboratory of Environmental Catalysis and Pollution Control, School of Environmental Science and Engineering, Institute of Environmental Health and Pollution Control, Guangdong University of Technology, Guangzhou 510006, China

Jianfei Peng - Tianjin Key Laboratory of Urban Transport Emission Research, College of Environmental Science and Engineering, Nankai University, Tianjin 300071, China

Yuying Wang - School of Atmospheric Physics, Nanjing University of Information Science \& Technology, Nanjing, Jiangsu 210044, China

Chunyu Wang - Department of Automation, University of Science and Technology of China, Hefei, Anhui 230022, China

Fang Zhang - State Key Laboratory of Earth Surface Processes and Resource Ecology, College of Global Change and Earth
System Science, Beijing Normal University, Beijing 100875, China

Yuxuan Wang - Department of Earth and Atmospheric Sciences, University of Houston, Houston, Texas 77004, United States

John H. Seinfeld - Division of Chemistry and Chemical Engineering, California Institute of Technology, Pasadena, California 91125, United States; 이이.org/0000-00031344-4068

Complete contact information is available at:

https://pubs.acs.org/10.1021/acs.est.0c08066

\section{Author Contributions}

Y.L. and Y.J. contributed equally to this work. R.Z. conceived and supervised the work. Y.L. designed the experimental system and protocols and collected data. R.Z. and Y.L. drafted and revised the manuscript. J.H.S. helped draft and revise the manuscript. All authors analyzed the data, approved the final version, and agreed to be accountable for all aspects of the work.

Notes

The authors declare no competing financial interest.

\section{ACKNOWLEDGMENTS}

Y.J. acknowledges the support by the National Natural Science Foundation of China Grants (41731279 and 41675122), Local Innovative and Research Teams Project of Guangdong Pearl River Talents Program (2017BT01Z032), Natural Science Foundation of Guangdong Province, China (2019B151502064), and Science and Technology Program of Guangzhou City (201707010188). R.Z. acknowledges the support by the Robert A. Welch Foundation (Grant A-1417). Y.L. was supported by a dissertation Fellowship at Texas A\&M University.

\section{REFERENCES}

(1) Zhang, R.; Wang, G.; Guo, S.; Zamora, M. L.; Ying, Q.; Lin, Y.; Wang, W.; Hu, M.; Wang, Y. Formation of Urban Fine Particulate Matter. Chem. Rev. 2015, 115, 3803-3855.

(2) Seinfeld, J. H.; Pandis, S. N. Atmospheric Chemistry and Physics: From Air Pollution to Climate Change; John Wiley \& Sons, 2016.

(3) Intergovernmental Panel on Climate Change (IPCC). Climate Change 2013: The Physical Science Basis. Contribution of Working Group I to the Fifth Assessment Report of the Intergovernmental Panel on Climate Change; Cambridge University Press, 2013.

(4) National Academies of Sciences, Engineering, and Medicine. The Future of Atmospheric Chemistry Research: Remembering Yesterday, Understanding Today, Anticipating Tomorrow; The National Academies Press: Washington, D. C., 2016.

(5) Jimenez, J. L.; Canagaratna, M. R.; Donahue, N. M.; Prevot, A. S. H.; Zhang, Q.; Kroll, J. H.; DeCarlo, P. F.; Allan, J. D.; Coe, H.; Ng, N. L.; Aiken, A. C.; Docherty, K. S.; Ulbrich, I. M.; Grieshop, A. P.; Robinson, A. L.; Duplissy, J.; Smith, J. D.; Wilson, K. R.; Lanz, V. A.; Hueglin, C.; Sun, Y. L.; Tian, J.; Laaksonen, A.; Raatikainen, T.; Rautiainen, J.; Vaattovaara, P.; Ehn, M.; Kulmala, M.; Tomlinson, J. M.; Collins, D. R.; Cubison, M. J.; Dunlea, J.; Huffman, J. A.; Onasch, T. B.; Alfarra, M. R.; Williams, P. I.; Bower, K.; Kondo, Y.; Schneider, J.; Drewnick, F.; Borrmann, S.; Weimer, S.; Demerjian, K.; Salcedo, D.; Cottrell, L.; Griffin, R.; Takami, A.; Miyoshi, T.; Hatakeyama, S.; Shimono, A.; Sun, J. Y.; Zhang, Y. M.; Dzepina, K.; Kimmel, J. R.; Sueper, D.; Jayne, J. T.; Herndon, S. C.; Trimborn, A. M.; Williams, L. R.; Wood, E. C.; Middlebrook, A. M.; Kolb, C. E.; Baltensperger, U.; Worsnop, D. R. Evolution of Organic Aerosols in the Atmosphere. Science 2009, 326, 1525-1529. 
(6) Guo, S.; Hu, M.; Zamora, M. L.; Peng, J.; Shang, D.; Zheng, J.; Du, Z.; Wu, Z.; Shao, M.; Zeng, L.; Molina, M. J.; Zhang, R. Elucidating Severe Urban Haze Formation in China. Proc. Natl. Acad. Sci. U.S.A. 2014, 111, 17373-17378.

(7) Heald, C. L.; Jacob, D. J.; Park, R. J.; Russell, L. M.; Huebert, B. J.; Seinfeld, J. H.; Liao, H.; Weber, R. J. A Large Organic Aerosol Source in the Free Troposphere Missing from Current Models. Geophys. Res. Lett. 2005, 32, No. L18809.

(8) Shrivastava, M.; Cappa, C. D.; Fan, J.; Goldstein, A. H.; Guenther, A. B.; Jimenez, J. L.; Kuang, C.; Laskin, A.; Martin, S. T.; Ng, N. L.; Petaja, T.; Pierce, J. R.; Rasch, P. J.; Roldin, P.; Seinfeld, J. H.; Shilling, J.; Smith, J. N.; Thornton, J. A.; Volkamer, R.; Wang, J.; Worsnop, D. R.; Zaveri, R. A.; Zelenyuk, A.; Zhang, Q. Recent Advances in Understanding Secondary Organic Aerosol: Implications for Global Climate Forcing. Rev. Geophys. 2017, 55, 509-559.

(9) Hodzic, A.; Kasibhatla, P. S.; Jo, D. S.; Cappa, C. D.; Jimenez, J. L.; Madronich, S.; Park, R. J. Rethinking the Global Secondary Organic Aerosol (SOA) Budget: Stronger Production, Faster Removal, Shorter Lifetime. Atmos. Chem. Phys. 2016, 16, 7917-7941.

(10) Heald, C. L.; Kroll, J. H. The fuel of atmospheric chemistry: Toward a complete description of reactive organic carbon. Sci. Adv. 2020, 6, No. eaay 8967

(11) Marrero-Ortiz, W.; Hu, M.; Du, Z.; Ji, Y.; Wang, Y.; Guo, S.; Lin, Y.; Gomez-Hermandez, M.; Peng, J.; Li, Y.; Secrest, J.; Zamora, M. L.; Wang, Y.; An, T.; Zhang, R. Formation and Optical Properties of Brown Carbon from Small $\alpha$-Dicarbonyls and Amines. Environ. Sci. Technol. 2019, 53, 117-126.

(12) Moise, T.; Flores, J. M.; Rudich, Y. Optical Properties of Secondary Organic Aerosols and Their Changes by Chemical Processes. Chem. Rev. 2015, 15, 4400-4439.

(13) Jang, M.; Czoschke, N. M.; Lee, S.; Kamens, R. M. Heterogeneous Atmospheric Aerosol Production by Acid-Catalyzed Particle-Phase Reactions. Science 2002, 298, 814-817.

(14) Rudich, Y.; Donahue, N. M.; Mentel, T. F. Aging of Organic Aerosol: Bridging the Gap Between Laboratory and Field Studies. Annu. Rev. Phys. Chem. 2007, 58, 321-352.

(15) Tan, Y.; Carlton, A. G.; Seitzinger, S. P.; Turpin, B. J. SOA from methylglyoxal in clouds and wet aerosols: Measurement and prediction of key products. Atmos. Environ. 2010, 44, 5218-5226.

(16) Zhang, R.; Suh, I.; Zhao, J.; Zhang, D.; Fortner, E. C.; Tie, X.; Molina, L. T.; Molina, M. J. Atmospheric New Particle Formation Enhanced by Organic Acids. Science 2004, 304, 1487-1490.

(17) Zhang, R.; Wang, L.; Khalizov, A. F.; Zhao, J.; Zheng, J.; McGraw, R. L.; Molina, L. T. Formation of Nanoparticles of Blue Haze Enhanced by Anthropogenic Pollution. Proc. Natl. Acad. Sci. U.S.A. 2009, 106, 17650-17654.

(18) Ji, Y.; Zhao, J.; Terazono, H.; Misawa, K.; Levitt, N. P.; Li, Y.; Lin, Y.; Peng, J.; Wang, Y.; Duan, L.; Pan, B.; Zhang, F.; Feng, X.; An, T.; Marrero-Ortiz, W.; Secrest, J.; Zhang, A. L.; Shibuya, K.; Molina, M. J.; Zhang, R. Reassessing the Atmospheric Oxidation Mechanism of Toluene. Proc. Natl. Acad. Sci. U.S.A. 2017, 114, 8169-8174.

(19) Zhao, J.; Zhang, R.; Misawa, K.; Shibuya, K. Experimental product study of the $\mathrm{OH}$-initiated oxidation of $\mathrm{m}$-xylene. J. Photochem. Photobiol., A 2005, 176, 199-207.

(20) Ji, Y.; Zheng, J.; Qin, D.; Li, Y.; Gao, Y.; Yao, M.; Chen, X.; Li, G.; An, T.; Zhang, R. OH-Initiated Oxidation of Acetylacetone: Implications for Ozone and Secondary Organic Aerosol Formation. Environ. Sci. Technol. 2018, 52, 11169-11177.

(21) Fu, T. M.; Jacob, D. J.; Wittrock, F.; Burrows, J. P.; Vrekoussis, M.; Henze, D. K. Global Budgets of Atmospheric Glyoxal and Methylglyoxal, and Implications for Formation of Secondary Organic Aerosols. J. Geophys. Res.: Atmos. 2008, 113, No. D15303.

(22) Tan, Y.; Lim, Y. B.; Altieri, K. E.; Seitzinger, S. P.; Turpin, B. J. Mechanisms leading to oligomers and SOA through aqueous photooxidation: insights from $\mathrm{OH}$ radical oxidation of acetic acid and methylglyoxal. Atmos. Chem. Phys. 2012, 11, 18319-18347.

(23) Lim, Y. B.; Tan, Y.; Turpin, B. J. Chemical insights, explicit chemistry and yields of secondary organic aerosol from methylglyoxal and glyoxal. Atmos. Chem. Phys. 2013, 13, 4687-4725.
(24) Lim, Y. B.; Tan, Y.; Perri, M. J.; Seitzinger, S. P.; Turpin, B. J. Aqueous chemistry and its role in secondary organic aerosol (SOA) formation. Atmos. Chem. Phys. 2010, 10, 10521-10529.

(25) Loeffler, K. W.; Koehler, C. A.; Paul, N. M.; De Haan, D. O. Oligomer Formation in Evaporating Aqueous Glyoxal and Methyl Glyoxal Solutions. Environ. Sci. Technol. 2006, 40, 6318-6323.

(26) Volkamer, R.; Jimenez, J. L.; San Martini, F.; Dzepina, K.; Zhang, Q.; Salcedo, D.; Molina, L. T.; Worsnop, D. R.; Molina, M. J. Secondary Organic Aerosol Formation from Anthropogenic Air Pollution: Rapid and Higher than Expected. Geophys. Res. Lett. 2006, 33, No. L17811.

(27) Kalberer, M.; Paulsen, D.; Sax, M.; Steinbacher, M.; Dommen, J.; Prevot, A. S. H.; Fisseha, R.; Weingartner, E.; Frankevich, V.; Zenobi, R.; Baltensperger, U. Identification of Polymers as Major Components of Atmospheric Organic Aerosols. Science 2004, 303, $1659-1662$

(28) Kroll, J. H.; Ng, N. L.; Murphy, S. M.; Varutbangkul, V.; Flagan, R. C.; Seinfeld, J. H. Chamber Studies of Secondary Organic Aerosol Growth by Reactive Uptake of Simple Carbonyl Compounds. J. Geophys. Res.: Atmos. 2005, 110, No. D23207.

(29) Wang, L.; Xu, W.; Khalizov, A. F.; Zheng, J.; Qiu, C.; Zhang, R. Laboratory Investigation on the Role of Organics in Atmospheric Nanoparticle Growth. J. Phys. Chem. A 2011, 115, 8940-8947.

(30) Wang, L.; Khalizov, A. F.; Zheng, J.; Xu, W.; Ma, Y.; Lal, V.; Zhang, R. Atmospheric Nanoparticles Formed from Heterogeneous Reactions of Organics. Nat. Geosci. 2010, 3, 238-242.

(31) De Haan, D. O.; Hawkins, L. N.; Welsh, H. G.; Pednekar, R.; Casar, J. R.; Pennington, E. A.; de Loera, A.; Jimenez, N. G.; Symons, M. A.; Zauscher, M.; Pajunoja, A.; Caponi, L.; Cazaunau, M.; Formenti, P.; Gratien, A.; Pangui, E.; Doussin, J. F. Brown Carbon Production in Ammonium- or Amine-Containing Aerosol Particles by Reactive Uptake of Methylglyoxal and Photolytic Cloud Cycling. Environ. Sci. Technol. 2017, 51, 7458-7466.

(32) Zhao, J.; Levitt, N. P.; Zhang, R.; Chen, J. M. Heterogeneous reactions of methylglyoxal in acidic media: Implications for secondary organic aerosol formation. Environ. Sci. Technol. 2006, 40, 76827687.

(33) Gomez, M. E.; Lin, Y.; Guo, S.; Zhang, R. Heterogeneous Chemistry of Glyoxal on Acidic Solutions. An Oligomerization Pathway for Secondary Organic Aerosol Formation. J. Phys. Chem. A 2015, 119, 4457-4463.

(34) De Haan, D. O.; Jimenez, N. G.; de Loera, A.; Cazaunau, M.; Gratien, A.; Pangui, E.; Doussin, J.-F. Methylglyoxal Uptake Coefficients on Aqueous Aerosol Surfaces. J. Phys. Chem. A 2018, 122, 4854-4860.

(35) De Haan, D. O.; Hawkins, L. N.; Kononenko, J. A.; Turley, J. J.; Corrigan, A. L.; Tolbert, M. A.; Jimenez, J. L. Formation of NitrogenContaining Oligomers by Methylglyoxal and Amines in Simulated Evaporating Cloud Droplets. Environ. Sci. Technol. 2011, 45, 984991.

(36) Khalizov, A. F.; Lin, Y.; Qiu, C.; Guo, S.; Collins, D.; Zhang, R. Role of $\mathrm{OH}$-initiated oxidation of isoprene in aging of combustion soot. Environ. Sci. Technol. 2013, 47, 2254-2263.

(37) Guo, S.; Hu, M.; Lin, Y.; Gomez-Hernandez, M.; Zamora, M. L.; Peng, J.; Collins, D. R.; Zhang, R. OH-Initiated oxidation of mxylene on black carbon aging. Environ. Sci. Technol. 2016, 50, 86058612.

(38) Hua, W.; Jubb, A. M.; Allen, H. C. Electric Field Reversal of $\mathrm{Na}_{2} \mathrm{SO}_{4},\left(\mathrm{NH}_{4}\right)_{2} \mathrm{SO}_{4}$, and $\mathrm{Na}_{2} \mathrm{CO}_{3}$ Relative to $\mathrm{CaCl}_{2}$ and $\mathrm{NaCl}$ at the Air/Aqueous Interface Revealed by Phase-Sensitive Sum Frequency. J. Phys. Chem. Lett. 2011, 2, 2515-2520.

(39) Ji, Y.; Shi, Q.; Li, Y.; An, T.; Zheng, J.; Peng, J.; Gao, Y.; Chen, J.; Li, G.; Wang, Y.; et al. Carbenium Ion-Mediated Oligomerization of Methylglyoxal for Secondary Organic Aerosol Formation. Proc. Natl. Acad. Sci. U.S.A. 2020, 117, 13294-13299.

(40) Ravishankara, A. R. Heterogeneous and multiphase chemistry in the troposphere. Science 1997, 276, 1058-1065.

(41) Wang, G.; Zhang, R.; Gomez, M. E.; Yang, L.; Levy Zamora, M.; Hu, M.; Lin, Y.; Peng, J.; Guo, S.; Meng, J.; Li, J.; Cheng, C.; Hu, 
T.; Ren, Y.; Wang, Y.; Gao, J.; Cao, J.; An, Z.; Zhou, W.; Li, G.; Wang, J.; Tian, P.; Marrero-Ortiz, W.; Secrest, J.; Du, Z.; Zheng, J.; Shang, D.; Zeng, L.; Shao, M.; Wang, W.; Huang, Y.; Wang, Y.; Zhu, Y.; Li, Y.; Hu, J.; Pan, B.; Cai, L.; Cheng, Y.; Ji, Y.; Zhang, F.; Rosenfeld, D.; Liss, P. S.; Duce, R. A.; Kolb, C. E.; Molina, M. J. Persistent Sulfate Formation from London Fog to Chinese Haze. Proc. Natl. Acad. Sci. U.S.A. 2016, 113, 13630-13635.

(42) Shi, Q.; Zhang, W.; Ji, Y.; Wang, J.; Qin, D.; Chen, J.; Gao, Y.; Li, G.; An, T. Enhanced uptake of glyoxal at the acidic nanoparticle interface: implications for secondary organic aerosol formation. Environ. Sci. Nano 2020, 7, 1126-1135.

(43) Zhao, J.; Levitt, N. P.; Zhang, R. Heterogeneous chemistry of octanal and 2, 4-hexadienal with sulfuric acid. Geophys. Res. Lett. 2005, 32, No. L09802.

(44) Xu, W.; Gomez-Hernandez, M.; Guo, S.; Secrest, J.; MarreroOrtiz, W.; Zhang, A. L.; Zhang, R. Acid-Catalyzed Reactions of Epoxides for Atmospheric Nanoparticle Growth. J. Am. Chem. Soc. 2014, 136, 15477-15480.

(45) Waxman, E. M.; Elm, J.; Kurtén, T.; Mikkelsen, K. V.; Ziemann, P. J.; Volkamer, R. Glyoxal and Methylglyoxal Setschenow Salting Constants in Sulfate, Nitrate, and Chloride Solutions: Measurements and Gibbs Energies. Environ. Sci. Technol. 2015, 49, 11500-11508.

(46) Nozière, B.; Dziedzic, P.; Córdova, A. Products and kinetics of the liquid-phase reaction of glyoxal catalyzed by ammonium ions $\left(\mathrm{NH}_{4}^{+}\right)$. J. Phys. Chem. A 2009, 113, 231-237.

(47) Xu, W.; Guo, S.; Gomez-Hernandez, M.; Zamora, M. L.; Secrest, J.; Marrero-Ortiz, W.; Zhang, A. L.; Collins, D. R.; Zhang, R. Cloud Forming Potential of Oligomers Relevant to Secondary Organic Aerosols. Geophys. Res. Lett. 2014, 41, 6538-6545.

(48) Zhao, J.; Zhang, R.; Fortner, E. C.; North, S. W. Quantification of hydroxycarbonyls from OH-isoprene reactions. J. Am. Chem. Soc. 2004, 126, 2686-2687.

(49) An, Z.; Huang, R.-J.; Zhang, R.; Tie, X.; Li, G.; Cao, J.; Zhou, W.; Shi, Z.; Han, Y.; Gu, Z.; Ji, Y. Severe Haze in Northern China: A Synergy of Anthropogenic Emissions and Atmospheric Processes. Proc. Natl. Acad. Sci. U.S.A. 2019, 116, 8657-8666.

(50) Wang, G.; Zhang, F.; Peng, J.; Duan, L.; Ji, Y.; Marrero-Ortiz, W.; Wang, J.; Li, J.; Wu, C.; Cao, C.; Wang, Y.; Zheng, J.; Secrest, J.; Li, Y.; Wang, Y.; Li, H.; Li, N.; Zhang, R. Particle acidity and sulfate production during severe haze events in China cannot be reliably inferred by assuming a mixture of inorganic salts. Atmos. Chem. Phys. 2018, 18, 10123-10132.

(51) Peng, J.; Hu, M.; Shang, D.; Wu, Z.; Du, Z.; Tan, T.; Wang, Y.; Zhang, F.; Zhang, R. Explosive secondary aerosol formation during severe haze in the North China Plain. Environ. Sci. Technol. 2021, 55, 2189-2207.

(52) Goldstein, A. H.; Koven, C. D.; Heald, C. L.; Fung, I. Y. Biogenic Carbon and Anthropogenic Pollutants Combine to Form a Cooling Haze over the Southeastern United States. Proc. Natl. Acad. Sci. U.S.A. 2009, 106, 8835-8840.

(53) Guo, S.; Hu, M.; Peng, J.; Wu, Z.; Zamora, M. L.; Shang, D.; Du, Z.; Zheng, J.; Fang, X.; Tang, R.; Wu, Y.; Zeng, L.; Shuai, S.; Zhang, W.; Wang, Y.; Ji, Y.; Li, Y.; Zhang, A. L.; Wang, W.; Zhang, F.; Zhao, J.; Gong, X.; Wang, C.; Molina, M. J.; Zhang, R. Remarkable Nucleation and Growth of Ultrafine Particles from Vehicular Exhaust. Proc. Natl. Acad. Sci. U.S.A. 2020, 117, 3427-3432.

(54) Zhang, F.; Wang, Y.; Peng, J.; Chen, L.; Sun, Y.; Duan, L.; Ge, X.; Li, Y.; Zhao, J.; Liu, C.; Zhang, X.; Zhang, G.; Pan, Y.; Wang, Y.; Zhang, A. L.; Ji, Y.; Wang, G.; Hu, M.; Molina, M. J.; Zhang, R. An Unexpected Catalyst Dominates Formation and Radiative Forcing of Regional Haze. Proc. Natl. Acad. Sci. U.S.A. 2020, 117, 3960-3966. 